\title{
MOLECULAR ASPECTS OF CONTROL IN EPIDERMAL DIFFERENTIATION*
}

\author{
F. L. VAUGHAN and I. A. BERNSTEIN
}

From the Cellular Chemistry Laboratory of the Department of Environmental and Industrial Health and from the Department of Biological Chemistry, The University of Michigan, Ann Arbor, Michigan $48104^{* *}$

(Received for publication November 24, 1975)

\section{Summary}

The mammalian epidermis is organized into layers of structurally different cells-the basal, spinous, granular and cornified layers-which represent steps in the differentiative process that terminates in cornification and desquamation. Investigation of the molecular mechanisms that control this ordered sequence of events provides clues to the etiology of certain epidermal pathologies. DNA synthesis and mitosis are normally restricted to the basal layer. Several substances have been implicated in the mitotic control of epidermal cells, the loss of mitotic activity being the first major step in normal keratinization. Investigations performed in this laboratory indicate that isolated differentiated nuclei can replicate their DNA which they are inhibited from doing in situ. Addition of a high speed supernate from homogenized differentiated cells inhibited this synthetic activity in vitro suggesting the existence of a cytoplasmic inhibitor of DNA synthesis. It is not known whether mitotic inhibition in differentiated epidermal cells is a function of the inhibition of DNA replication.

Contrary to previous assumptions, recent experimental evidence clearly indicates that, unlike DNA synthesis, RNA synthesis occurs in differentiated cells. Correlated with this synthetic activity is the observation that a protein rich

\footnotetext{
* A submitted article.

** Mailing address: 1620 School of Public Health, The University of Michigan, Ann Arbor, Michigan 48104.
}

in histidine is specifically formed in the granular cells. This protein appears to be a component of the keratohyalin granules which fill the cells of the granular layer. Investigations were conducted in this laboratory to determine whether control of the synthesis of this protein occurs at the level of translation or transcription. Translation, in vitro, of mRNA obtained from isolated populations of each epidermal cell type suggested that control of protein synthesis in the differentiating epidermis is transcriptional, i.e. only in the granular cell is there an mRNA for the histidine-rich protein. Transcription, in vitro, of chormatin isolated from the separated cell populations produced RNA with a ratio of cytidine to uracil consistent with the predicted mRNA for this protein thus providing additional support for the hypothesis that epidermal differentiation is controlled at the level of 'gene-readout.'

\section{Introduction}

The mammalian epidermis, a tissue in which the cells are continuously differentiating during the life time of the animal, is organized into layers of structurally different cells that represent the progressive stages of keratinization (Fig. 1). Sitting upon the basement membrane, which separates the dermal and epidermal segments of the skin, are the columnar germinative cells of the epidermis referred to as basal cells. These cells are attached by half desmosomes to the 


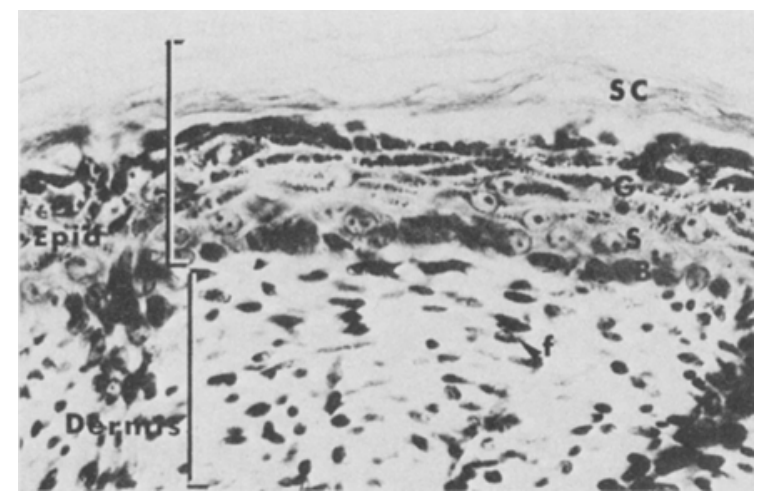

Fig. 1. Cross section of rat skin showing the dermis and epidermis (Epid). f, fibroblasts; $\mathrm{B}$, basal cell; $\mathrm{S}$, spinous cell; $\mathrm{G}$, granular cell; SC, stratum corneum.

basement membrane and by complete desmosomes with each other. The next identifiable cell type resulting from differentiation of the basal cells is referred to either as the spinous or prickle cell-so named because in early histological preparations cell shrinkage left the cells attached to each other by numerous desmosomes thus giving the cell a spinous or prickled appearance. The next stage of morphological differentiation is the granular cell which contains the so-called keratohyalin $(\mathrm{KH})$ granules of varying sizes and shapes. Finally and most superficially are the keratinized enucleated cells, i.e. the squamous cells which make up the cornified layer and which are constantly being lost from the tissue (desquamation). Because this tissue is organized in layers, it has been possible to obtain populations of cells at the various differentiative stages ${ }^{1,2}$.

Biochemical comparisons of these populations yield data which are relevant to the molecular mechanisms involved in the control and progression of normal epidermal differentiation and provide clues to the abnormalities in particular epidermal pathologies. Since epidermal differentiation in situ represents a terminal process, dedifferentiation appears not to be a significant problem and thus does not confuse the interpretation of biochemical results arising from such comparative studies.

\section{Structural and Functional Changes in the Epidermis}

DNA synthesis and mitosis are normally restricted to the cells of the deepest layer. In the newborn rat these processes occur in a single layer of cells attached to the basement membrane $^{3,4}$. In human epidermis, on the other hand, an incorporation of tritiated thymidine has been observed in cells immediately above the basal layer ${ }^{5}$ indicating that in this species all germinative cells are not attached to the basement membrane. As a result of this proliferation, a constant supply of keratinocytes is available to replace the cells which are lost at the surface of this tissue.

The first major differentiative event appears to be the cessation of mitosis which appears to coincide with a second event, the appearance of well organized tonofilaments. There is reason to believe that these two events are indeed related but the chronology and physiology of the relationship is unknown. Although the tonofilaments are seen first in cells of the basal layer, there is a significant increase in the number of these structures in the spinous cell. Tonofilaments persist in the remaining epidermal cell types. It is quite possible that the tonofilaments seen in the basal layer are in cells which have already ceased mitotic activity since the basal layer probably contains nongerminative as well as germinative cells.

The distinct morphological and physiological differences between the basal and spinous cell are easily demonstrated when these cells are separately observed in a liquid medium ${ }^{1}$. As diagrammed in Figure 2, the basal cell, in vitro, assumes a spherical shape, and has a large nuclear to cytoplasmic ratio, a concentrically located nucleus and a basophilic cytoplasm when stained with hemotoxylin and eosin. By comparison, the spinous cell generally appears to be flattened rather than spherical and has distinct angles in its cellular membrane indicating that this cell type is also more rigid than is the basal cell. This could be a result of the nature of the tonofilaments present and perhaps a consequence of structural changes in the cell's outer membrane. Also, in stained smears, the cytoplasm in these cells is less basophilic than in the basal cell, possibly reflecting a decrease in cytoplasmic elements involved in cell growth and proliferation.

A third event in differentiation is marked by the appearance of the basophilic $\mathrm{KH}$ granulesstructures containing newly synthesized protein having a high concentration of histidine. $\mathrm{KH}$ formation is first manifested by the presence of 


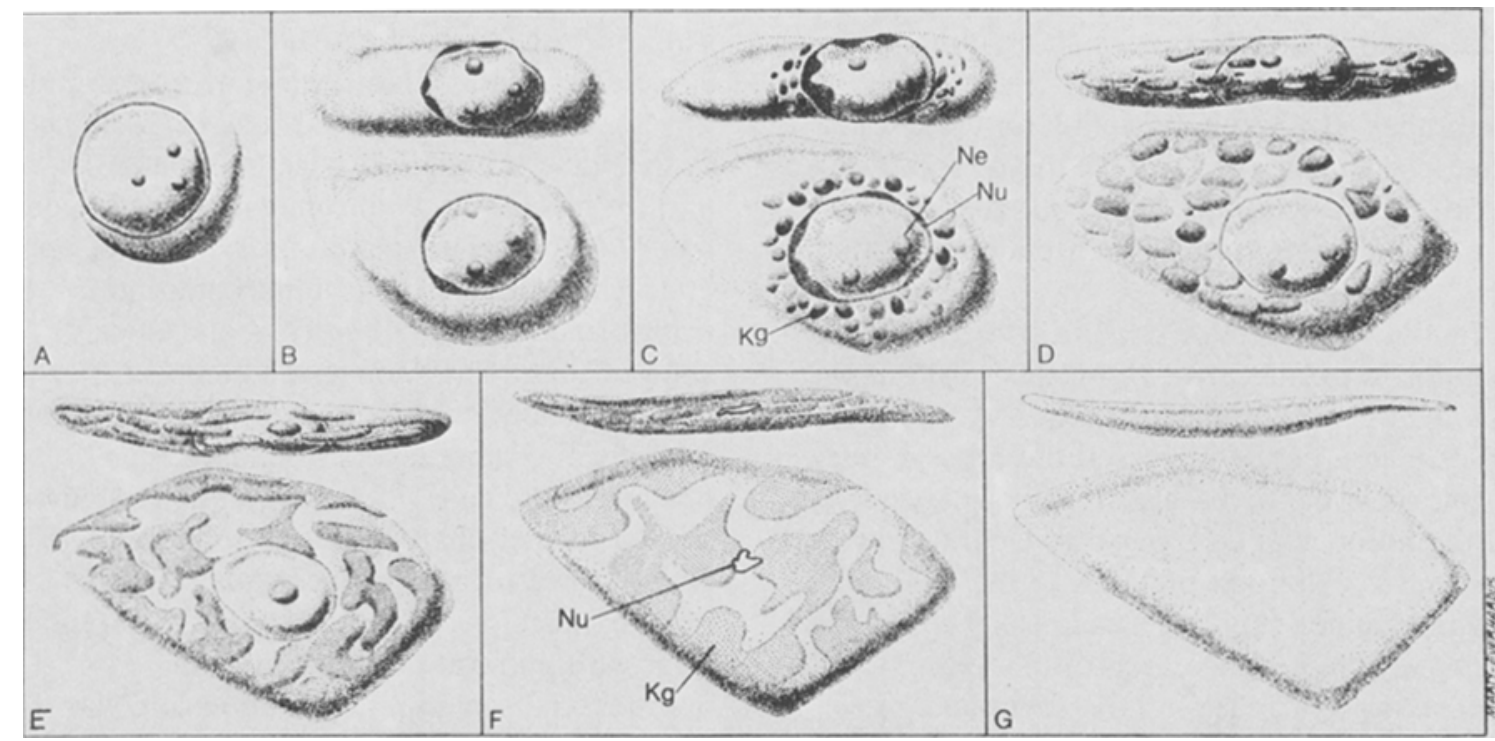

Fig. 2. Diagrammatic representation of isolated epidermal cells. A, basal cell; B, spinous cell (top drawing, cross sectional view; bottom drawing, flat view); C, early granular cell (GC) with small darkly staining keratohyalin granules (Kg); D, typical GC with large $\mathrm{Kg}$; $\mathrm{E}$, late $\mathrm{GC}$ with coalescing $\mathrm{Kg}$; F, late $\mathrm{GC}$ with a remnant nucleus and lightly staining $\mathrm{Kg}$; $\mathrm{G}$, desquamated, keratinized cell of the stratum corneum.

small granules and, as differentiation progresses, becomes more abundant resulting eventually in larger granules that appear throughout the cytoplasm. The nuclei in the most superficial cells of this layer show signs of degeneration as indicated by a progressive decrease in nuclear size. At this stage, the $\mathrm{KH}$ no longer stains darkly and seems to be spread evenly throughout the cell.

The total loss of the nucleus from the granular cell marks a fourth stage of differentiation and the formation of keratinous fibers in the cornified cells, a fifth stage. It has been proposed on morphological grounds that the tonofilaments and keratohyalin material combine to produce the fibers which completely fill the fully keratinized cell ${ }^{6}$. It is not known at this time whether or not this is true and if true, how it happens.

\section{Control of Mitosis in the Epidermis}

In the normal mammalian epidermis, cessation of mitosis is certainly an early step, if not the first step in the differentiative process. Differentiated cells also do not normally replicate their DNA. Mitotic inhibition may be accomplished by blocking DNA synthesis since the early differentiated cells have only a diploid level of
DNA $^{7}$. The validity of this proposal has yet to be tested.

Several substances which influence the proliferative activity of epidermal cells, have been described. One of these, the epidermal growth factor (EGF) first described by $\mathrm{COHEN}^{8}$, is a polypeptide which has a molecular weight of 6,045 daltons when isolated from the submaxillary glands of adult male mice. EGF stimulates the proliferation and keratinization of various epidermal tissues in vivo and in vitro ${ }^{9}$. Although the mechanism of these effects are not known, EGF has been shown to (1) stimulate protein and RNA synthesis ${ }^{10}$, (2) increase polysome formation ${ }^{11}$, enhance the incorporation of $\left[{ }^{3} \mathrm{H}\right]$ thymidine into $\mathrm{DNA}^{12}$ and (3) induce orithine decarboxylase ${ }^{13}$. EGF activity resides in a large complex composed of two units of EGF and two units of a binding protein (with molecular weight of 29,300 daltons) for a total molecular weight of 74,000 daltons ${ }^{14}$. The biological activity of the complex was found to be proportional to the amount of EGF present. The high molecular weight form of EGF may be an enzyme-product complex in which the substrate is 'EGF-precursor' and the binding protein is a specific arginine esterase which recognizes the substrate ${ }^{14}$. Low concentrations of EGF have been shown to stimulate DNA and 
RNA synthesis in human fibroblasts in vitro-an effect which is reversed by small amounts of cholera toxin ${ }^{15}$. Since the toxin binds to cell membranes, EGF may be acting on the membrane to decrease the level of cAMP and activate DNA synthesis ${ }^{15}$ thus possibly triggering events leading to mitosis in undifferentiated cells.

Vitamin A Acid (VAA) has also been shown to stimulate proliferative activity in vivo ${ }^{16}$ and in vitro ${ }^{17}$. Topical applications of VAA to the skin of hairless mice increased the mitotic index, the thickness of the basal and spinous layers and the number of cells per unit length of the epidermis $^{18}$. Addition of VAA to the medium on which guinea pig epidermal cells were grown in vitro resulted in increased cellular attachment and a six-fold increase in DNA synthesis as compared to controls ${ }^{18}$. The mode of action of VAA is not known. Prutkin ${ }^{19}$ studied the uptake of labeled VAA into the nucleus after topical application to rabbit hair follicle epidermis. He concluded that VAA, or its metabolite, is incorporated into the nucleus and influences protein synthesis. This phenomenon can be inhibited by actinomycin $\mathrm{D}$ if given prior to VAA application.

Another substance strongly implicated in mechanisms of cellular differentiation and function is $3^{\prime}, 5^{\prime}$-adenosine monophosphate (cAMP). This compound produces effects on target tissue similar to the effect of hormones and biogenic amines. Selectively in responsive cells, these latter substances stimulate the generation of cAMP by activating adenyl cyclase, which is membrane bound. This effect has been shown to occur in mouse epidermis ${ }^{20}$. The cAMP then activates subcellular effector devices which produce a series of different effects depending upon the target tissue involved ${ }^{21}$. cAMP has been shown to stimulate RNA and protein synthesis in the epithelial tissue of the uterus as do estrogens ${ }^{22}$. cAMP mimics the action of steroid hormones in inhibiting the growth of mammalian cells in vitro ${ }^{23}$. KRAM and TOMKINS ${ }^{24}$ have postulated a 'pleiotypic' control by cAMP on inhibiting uptake of amino acids, DNA synthesis, etc., which is antagonized by cGMP. These authors also suggested that cAMP regulates membrane transport by influencing the organization of microtubules since colcemid and vinblastine, but not cytochalasin $B$, reverse the inhibition of transport produced by cAMP without affecting levels of cAMP.

Recently, cAMP has been shown to stimulate development in normal cells e.g. (1) stalk cells in the slime mold ${ }^{25}$, (2) flagella in bacteria ${ }^{26}$, and (3) melanoblasts into melanocytes in gold $\mathrm{fish}^{27}$. Also intriguing are observations of apparent cAMP stimulation of differentiation in transformed cells in vitro. HsIE and $\mathrm{PuCK}^{28}$ showed that cAMP converted compact, randomly oriented and multilayered Chinese hamster cells into monolayers of elongated, fibroblast-like cells. Later experiments demonstrated further changes in the differentiated state of transformed Chinese hamster cells, i.e. reappearance of contact inhibition, reorientation of growth pattern, disappearance of pseudopodal structures, induction of collagen synthesis, and decrease in agglutinability by plant agglutinins and specific antibody ${ }^{29}$.

Yet another substance that may play an important role in regulating epidermal proliferation is the so-called "chalone" first described by Bullough $^{30}$. Since this first paper, numerous reports have appeared which support the existence of some substance in skin, which inhibits mitosis of the epithelium both in vitro and in vivo ${ }^{31-34}$. Chalone has been found to be tissuespecific but not species-specific ${ }^{31,35}$ and to require the participation of stress hormones ${ }^{31}$, although the latter observation has been questioned by other investigators ${ }^{34,36}$. Investigations into the effects, mode of action and significance of chalone as it affects the epidermis have been hampered by the unavailability of the pure substance. The antimitotic activity has been tentatively associated with a glycoprotein ${ }^{37}$ but efforts to purify the molecule have not been successful. Investigations have also been carried out to determine the site of action of chalone in the cell cycle. It is possible that there are two epidermal chalones since ELGJO, LAERUM and EDGEHILL, have reported a $G_{1}$ inhibitor in the differentiated layers ${ }^{38}$ and $a G_{2}$ inhibitor in the basal layer ${ }^{39}$ of the mouse epidermis. The mechanism of action of these inhibitory substances appear very comple ${ }^{40}$ and much work remains to be done before the significance of the chalone concept can be assessed.

VAUGHAN and BERNSTEIN ${ }^{1}$ initiated a study of mitotic inhibition in the differentiating epidermis by first asking whether or not the cessation 
of mitosis is reversible or more precisely, whether or not a differentiated cell can divide when taken out of the environment of the organized tissue and put in a proper supportive environment, in vitro. The experimental approach was to investigate whether differentiated cells could be cultured as a monolayer under the conditions which were successful with basal cells. To form a monolayer, of course cells have to divide. When a $0.25 \%$ suspension of basal cells obtained by trypsinization, was cultivated on glass in MEM and 10\% fetal calf serum, a monolayer routinely developed and confluence was reached in 5-6 days. But in over 50 attempts, although the cells originally adhered to the glass, populations of differentiated cells did not proliferate. The presence of an external, non-specific inhibitor in the suspension of differentiated cells, was ruled out by successfully culturing basal cells in the presence of differentiated cells. These data were interpreted as indicating that an inherent permanent change was responsible for the cessation of mitosis in epidermal differentiation.

Since differentiated cells also do not synthesize DNA in the intact skin, experiments were conducted to determine whether or not these cells could replicate their DNA in vitro. In contrast to basal cells, differentiated cells displayed little or no significant incorporation of $\left[{ }^{3} \mathrm{H}\right]$ thymidine into DNA when incubated at $35^{\circ}$ in MEM (without serum) containing the tracer ${ }^{1}$. The fact that in vitro differentiated cells not only did not divide but, as in situ, did not replicate their nuclear DNA, suggested that the mitotic block might be a function of a block in the synthesis of DNA.

The investigation then focused on whether the differentiated nucleus retained the enzymatic capability to synthesize DNA as measured by the incorporation of $\left[{ }^{3} \mathrm{H}\right]$ thymidine into the nucleic acid. Isolated nuclei from differentiated cells incorporated significant levels of the tracer as did nuclei from basal cells ${ }^{41}$. Nuclei were obtained by sedimentation from homogenates made in MEM containing $2.5 \%$ bovine serum albumin (BSA) and $0.002 \mathrm{M}$ EDTA. Figure 3 indicates the incorporation of $\left[{ }^{3} \mathrm{H}\right]$ thymidine by differentiated whole cells and by nuclei isolated from the same number of differentiated cells. Autoradiography confirmed that although whole differentiated cells contained label, no concen-

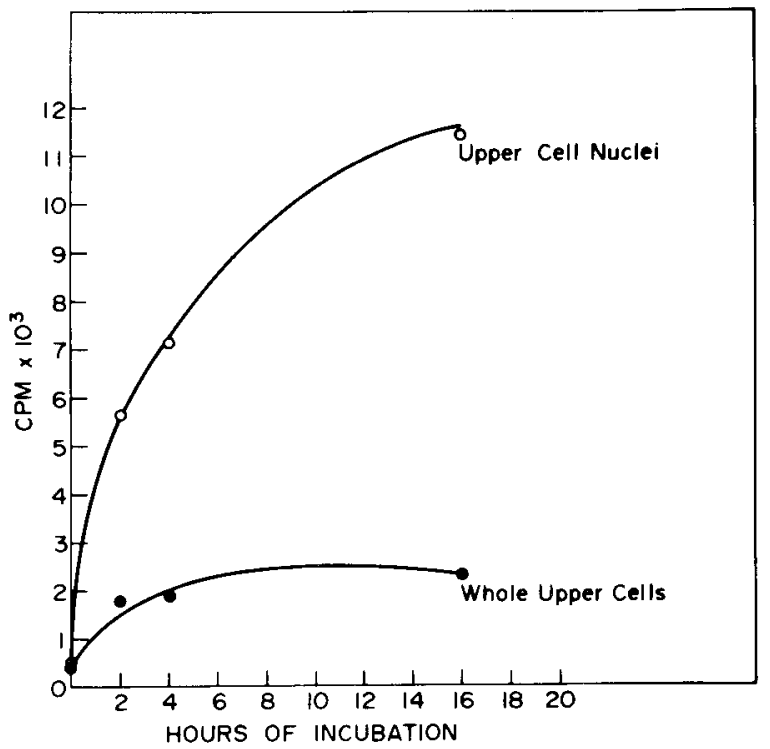

Fig. 3. The incorporation of $\left[{ }^{3} \mathrm{H}\right]$ thymidine by upper cells and upper cell nuclei. Upper cells include spinous and granular cells ${ }^{41}$

tration of grains occurred over nuclei in these cells whereas a significant number of free nuclei were labeled ${ }^{41}$. Most interesting was the observation that the addition of a high speed supernate from homogenized differentiated cells inhibited the incorporation of $\left[{ }^{3} \mathrm{H}\right]$ thymidine in both differentiated and basal nuclei. The nature of this inhibition is under investigation. Isolation of the inhibiting factor can be monitored by following its inhibitory influence on the incorporation of tritiated thymidine in free nuclei from either basal or differentiated cells.

The incorporation of thymidine into nuclei isolated from differentiated cells was not simply repair or chain elongation was shown by incubating the differentiated nuclei with $\left[{ }^{14} \mathrm{C}\right]$ bromodeoxyuridine, fractionating the DNA by neutral $\mathrm{CsCl}$ gradient ultracentrifugation, and showing that the double stranded DNA synthesized in the presence of bromodeoxyuridine had a significantly higher density than the DNA synthesized when thymidine was the precursor $^{41}$ (Fig. 4). Calculation by the method of KAROL and SIMPSON ${ }^{42}$ indicated that there had been a replacement of the order of at least $5 \%$ of the thymine by bromouracil. Alkaline $\mathrm{CsCl}$ gradient centrifugation demonstrated even more dramatically the increase in the density of DNA made in the presence of bromodeoxyuridine (Fig. 5). Apparently, the differentiated nucleus can replicate its DNA when it is outside 


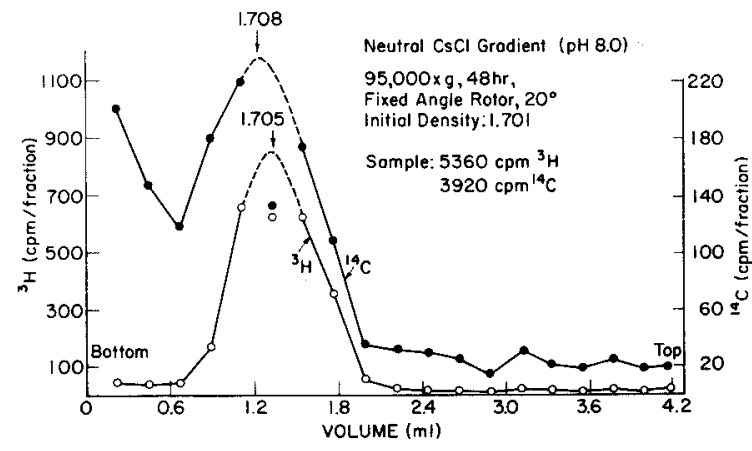

Fig. 4. Profile obtained by ultracentrifugation of $\left[{ }^{3} \mathrm{H}\right]$ thymidine and $\left[{ }^{14} \mathrm{C}\right]$ bromodeoxyuridine labeled DNA in a neutral cesium chloride density gradient. The number over the peak fraction indicates the density at that point in the gradient $^{41}$.

the cell but is inhibited from doing so in situ-possibly by the factor found in the highspeed supernate.

\section{Control of Protein Synthesis in Epidermal Differentiation}

Prior to the last 10 years, most cutaneous physiologists assumed that the differentiative changes seen in the mammalian epidermis simply represented degradation in a 'dying' system. Inconsistent with this view were the autoradiographic results obtained by FUKUYAMA and colleagues ${ }^{3,43}$ who showed that in the epidermis of the newborn rat, although nuclear DNA replication occurred only in the basal layer, RNA synthesis occurred in the nucleoli of all viable cells. This observation suggested that protein synthesis could occur in epidermal differentiated cells as well as in the geminative cells .Subsequent studies confirmed this hypothesis ${ }^{44}$.

When various amino acids were given intraperitoneally to newborn rats and $1 \mathrm{hr}$ later, the skin was removed and autoradiographs

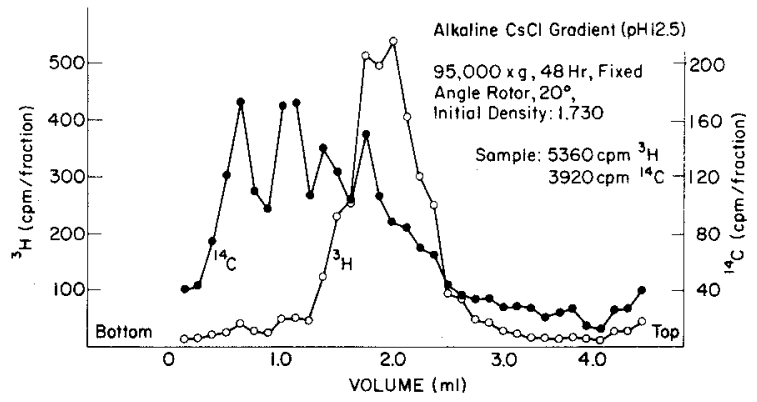

Fig. 5. Profile obtained by ultracentrifugation of $\left[{ }^{3} \mathrm{H}\right]$ thymidine and $\left[{ }^{14} \mathrm{C}\right]$ bromodeoxyuridine labeled DNA in an alkaline cesium chloride density gradient ${ }^{41}$. made, it was found ${ }^{44,45}$ that some amino acids first entered protein in the basal cells while other amino acids initially concentrated in the granular cells. Table I lists the various amino acids studied and where they first appeared. It should be noted that the epidermis is avascular so histidine, for example, must diffuse up through the lower cells to reach the site of incorporation seen initially in the upper cells. Since ReAven and $\mathrm{Cox}^{46}$ had already published information suggesting that granular cells had an unusual concentration of histidine, HOOBER and BERNSTEIN ${ }^{47}$ undertook to determine the nature of the protein in the granular cells responsible for this unusual rapid incorporation of $\left[{ }^{3} \mathrm{H}\right]$ histidine in the granular layer.

TABLE I

Location of initial epidermal incorporation of tritiated amino acids in the newborn rat.

\begin{tabular}{ll} 
& \multicolumn{2}{c}{ in vivo 44,45} \\
\hline Basal-lower spinous & Upper spinousingranular \\
\hline Leucine & Glycine \\
Phenylalanine & Histidine \\
Valine & Arginine \\
Lysine & Cystine \\
Methionine & Serine \\
Tyrosine & Tyrosine \\
Proline & Proline
\end{tabular}

Tracer administered by intraperitoneal injection,

Table II indicates the amino acid composition of a histidine-rich protein (HP) which was isolated from granular cells ${ }^{48}$ and which contained nearly $60 \%$ of the $\left[{ }^{3} \mathrm{H}\right]$ histidine present in the epidermis but less than $9 \%$ of the urea-extractable protein. (Keratin, the largest protein component of the epidermis, is not urea-extractable.) Note the presence in HP of amino acids which FUKUYAMA et al. ${ }^{44,45}$ first saw in the upper cells and the absence of leucine, pheylalanine and valine which first incorporated in the lower cells.

SIBRACK ${ }^{48}$ found that HP is synthesized in the extra-granular cytoplasm and then incorporated 
TABLE II 48

HP from KH: Amino acid composition and possible codons in mRNA

\begin{tabular}{|c|c|c|}
\hline Amino Acid & Residues/100 Residues & Possible Codons\# \\
\hline Glutamate & 22,40 & GAA GAG \\
\hline (glutamine) & $\star$ & (CAA CAG) \\
\hline Serine & 15,60 & UCU UCC UCA UCG AGU AGC \\
\hline Glycine & 13,10 & GGU GGC GGA GGG \\
\hline Arginine & 12,70 & CGU CGC CGA CGG AGA AGG \\
\hline Alanine & 11,00 & GCU GCC GCA GCG \\
\hline Histidine & 7,35 & CAU CAC \\
\hline Threonine & 6,08 & ACU ACC ACA ACG \\
\hline Aspartate & 4,82 & GAU GAC \\
\hline (asparagine) & $\star$ & (AAU AAC) \\
\hline Proline & 2,57 & $\operatorname{CCU~CCC~CCA~CCG~}$ \\
\hline Tyrosine & 1,09 & UAU UAC \\
\hline Isoleucine & 1,84 & AUU AUC AUA \\
\hline Lysine & 0,55 & AAA AAG \\
\hline Valine & $0,4 \mathrm{I}$ & GUU GUC GUA GUG \\
\hline
\end{tabular}

into macroaggregates of $\mathrm{KH}$ material ${ }^{*}$ isolated by the method of UGEL ${ }^{50}$. In Kh the HP constitutes about $50 \%$ of the granular protein. The size of the HP as isolated from $\mathrm{KH}$ and from the extra-granular cytoplasm was found to be 390,000 and 190,000 daltons, respectively. HP appears to be made up of a single size of monomer having a molecular weight of 15,000 16,500 daltons. SUGAWARA and BERNSTEIN ${ }^{51}$ have shown that synthesis of HP proceeds in two steps. A monomer synthesized in a ribosomal system which is inhibited by puromycin, is polymerized in a puromycin-insensitive step.

Thus there is a molecular process in which the ribosomal synthesis of a protein, HP, appears to be associated with the biogenesis of a morphological entity, $\mathrm{KH}$, and one can study the control mechanisms for the production of a gene-product which is involved in a specific differentiative event. One can ask, for example, whether the synthesis of HP in terms of differentiation is controlled at the level of transcription or translation.

*MatoltsY ${ }^{49}$ does not agree that the macroaggregates isolated by the method of $\mathrm{UGEL}^{50}$ represent $\mathrm{KH}$ material. Immunocytochemical ultrastructural studies are under way in this laboratory to investigate this difference of opinion.
Preliminary data have now been obtained on this question. Populations of basal and granular cells were isolated by the method of VAUGHAN and BERNSTEIN ${ }^{1}$. Messenger RNA (mRNA) from each populatimon was obtained from polyribosomes by the method of KUMAROo et al..$^{52}$ as well as directly from the post-mitochondrial cellular fraction and purified using oligo-dTcellulose $^{53}$ and each mRNA was translated in a cell free-protein synthesizing system to determine which mRNA coded for HP. If mRNA from both populations code for HP then the control has to be translational. If only the mRNA from granular cells codes for $\mathrm{HP}$, the control is probably exerted at the level of transcription. Since antibody against HP was unavailable for use as an assay for formation of the protein in the cell free system, a less specific assay had to be used. The ratio of histidine to leucine incorporation was compared inasmuch as HP has a high concentration of histidine but no leucine. If mRNA for HP is present only in the upper cells then the histidine/leucine incorporation ratio would be expected to be much higher when mRNA from the upper cells was used in contrast to mRNA from the lower cells. In fact, the ratio of histidine to leucine incorporation was 3 times greater when mRNA from the upper cells was used ${ }^{54}$. Equal amounts of mRNA were taken in each case. Although these data speak for control at the stage of transcription they are not definitive since identification of the nature of the protein made from granular cell mRNA has not yet been ascertained.

Furthermore it is possible that mRNA might be synthesized in all cells but not processed in the lower cells to a state in which it would be isolated by the procedure used. To answer this latter objection, SACHS and BERNSTEIN ${ }^{55}$ tried to determine whether the cistron for HP in DNA in nuclear chromatin was 'open' for transcription in upper cells and 'closed' in lower cells. Chromatin was isolated by Bonner's technique ${ }^{56}$ from cells of the entire epidermis, from a mixture of spinous and granular cells and from the granular cells alone and transcribed into mRNA using an E. coli DNA dependent, RNA polymerase.

Table II shows the composition of HP and the codons for each amino acid. Consideration of the composition of HP and the codons required to direct synthesis of this protein 
indicates that mRNA for HP would include a great deal of cytosine $(\mathrm{C})$ but very little uracil (U). In fact a calculation of the $\mathrm{C} / \mathrm{U}$ ratio in mRNA for HP would be 2.0 if one constructs an mRNA for HP based upon the amino acid composition and assumes random use of all appropriate codons and the absence of amides in HP. (Reliable data are not available on the amounts of glutamic and aspartic acids present as their amides.) Similar considerations for epidermal protein isolated from the entire epidermis indicates that the $\mathrm{C} / \mathrm{U}$ ratio in $\mathrm{mRNA}$ would be about $1: 1$. A representative experiment resulted in data that indicated the ratio of $\mathrm{C}: \mathbf{U}$ to be $1: 1$ for whole epidermal chromatin and 2.4 from granular cells.

These data then, taken together with those from the experiments with mRNA are consistent with the view that control of protein synthesis in the differentiating epidermis is transcriptional as appears to be the case in other differentiating and developing mammalian systems, e.g. the globin ${ }^{57,58}$ and foetoprotein ${ }^{59}$ synthesizing systems. It is still necessary to hold an open mind, however, until it has been unequivocally demonstrated that the RNA made from granular cell chromatin is a mRNA for HP in a cell-free protein synthesizing system.

Most exciting is the isolation of chromatins from cells at different stages of differentiation which are capable of being transcribed into different mRNA species for different proteins. Now one can attempt to compare structural aspects of the chromatins to determine the molecular nature of the control exerted for the synthesis of different proteins at different stages of epidermal differentiation.

\section{Acknowlegements}

Work in the authors' laboratory is supported by Grants AM 05268 and AM 15206, National Institutes of Health, U. S. Public Health Service.

\section{References}

1. Vaughan, F. L. and Bernstein, I. A. 1971. J. Invest. Derm. 56, 454-466.

2. Stern, I. B. and Sekeri-Pataryas, K. H. 1972. J. Invest. Derm. 59, 251-259.
3. Fukuyama, K. and Bernstein, I. A. 1961. J. Invest. Derm. 36, 321-326.

4. Wessells, N. K. 1963. Exp. Cell Res. 30, 36-55.

5. Penneys, N. S., Fulton, J. E., Weinstein, G. D. and Frost, P. 1970. Arch. Derm. 101, 323-327.

6. Brody, I. 1959. J. Ultrastructure Res. 2, 482-511.

7. Ehlers, G. Grunder, K. and Wohlrab, W. 1974. Arch. Derm. Forsch. 249, 255-276.

8. Cohen, S. 1962. J. Biological. Chem. 237, 1555-1562.

9. Cohen, S. 1964. Nat'l cancer Inst. Monogr. 13, 13.

10. Hoober, J. K. and Cohen, S. 1971. Biochem. Biophys. Acta 1968, 347-356.

11. Cohen, S. and Stastny, M. 1968. Biochem. Biophys. Acta 166, 427-437

12. Bertsch, S. and Marks, F. 1974. Nature 251, 517-519.

13. Stastny, M. and Cohen, S. 1970. Biochem. Biophys. Acta 204, 578-589.

14. Taylor, J. M., Mitchell, W. M. and Cohen, S. 1974. J. Biol. Chem. 249, 3198-3203.

15. Hollenberg, M. D. and Cuatrecasas, P. 1973. Proc. Nat'l Acad. Sci. 70, 2964-2968.

16. Stefan, J. 1972. J. Invest. Derm. 59, 228-232.

17. Wolff, H. H., Christophers, F. and Braun-Faleo, O. 1970. Arch. Klin. Exp. Dermatol. 237, 774-795.

18. Christophers, E. 1974. J. Invest. Derm. 63, 450-455.

19. Prutkin, L. and Bogart, B. 1970. J. Invest. Derm. 55, 249-255.

20. Marks, F. and Rebien, W. 1972. Biochem. Biophys. Acta $284,556-567$.

21. Sutherland, E. W. and Robison, G. A. 1966. Pharmol. Rev. 18, 145-161.

22. Hechter, O., Yoshinaga, K., Halkerston, I. D. K. 1967. Arch. Biochem. Biophys. 122, 449-465.

23. Ryan, W. L. and Heidrick, M. L. 1968. Science 162 , 1484-1485.

24. Kram, R. and Tomkins, G. M. 1973. Proc. Nat'l Acad. Sci. 70, 1659-1663.

25. Bonner, J. J. 1970. Proc. Nat'l Acad. Sci. 65, 110-113.

26. Yokota, T. and Gots, J. S. 1970. J. Bacteriol. 103, 513-516.

27. Chen, S. and Tchen, T. T. 1970 . Biochem. Biophys. Res. Comm. 41, 964-966.

28. Hsie, A. W. and Puck, T. T. 1971. Proc. Nat'l Acad. Sci. 68, 358-361.

29. Hsie, A. W. and Puck, T. T. 1971. Proc. Nat'l Acad. Sci. 68, 1648-1652.

30. Bullough, W. S. and Laurence, E. B. 1960. Proc. R. Soc. Lond. [Biol.] 151, 517-536.

31. Bullough, W. S., Laurence, E. B. Ivenson, O. H. and Elgjo, K. 1967. Nature 214, 578-580.

32. Elgjo, K. and Hennings, H. 1971. Virchows Arch. Abt. B. Zellpathol. 7, 1-7.

33. Frankfurt, O. S. 1971. Exp. Cell. Res. 64, 140-144.

34. Iverson, O. H., Randahl, E. and Elgjo, K. 1965. Acta. Path. Microbiol. Scand. 64, 506-510.

35. Iverson, O. H. 1968. Nature 219, 75.

36. Baden, H. P. and Suiokla, S. 1969. Exp. Cell Res. 50, 644-646.

37. Boldingh, W. H. and Laurence, E. B. 1968. Eur. J. Biochem. 5, 191-198.

38. Elgjo, K., Laerum, O. D. and Edgehill, W. 1972. Virchows Arch. [Zellpathol] 10, 229-236. 
39. Elgjo, K., Laerum, O. D. and Edgehill, W. 1971. Virchows Arch. [Zellpathol] 8, 277-283.

40. Argyris, T. S. 1972. Am. Zoologist 12, 137-149.

41. Vaughan, F. L. and Bernstein, I. A. 1972. J. Invest. Derm. 60, 245 (Abstract).

42. Karol, M. H. and Simpson, M. V. 1968. Science 162, 470-473.

43. Fukuyama, K. and Bernstein, I. A. 1963. J. Invest. Derm. 41, 47-52.

44. Fukuyama, K., Nakamura, T. and Bernstein, I. A. 1965. Anat. Rec. 152, 525-536.

45. Fukuyama, K. and Epstein, W. L. 1966. J. Invest. Derm. 47, 551-560.

46. Reaven, E. P. and Cox, A. J. 1966. Histochem. Cytochem. 11, 782-790.

47. Hoober, J. K. and Bernstein, I. A. 1966. Proc. Nat'l Acad. Sci., U.S., 56, 594-601.

48. Sibrack, L. A., Gray, R. H. and Bernstein, I. A. 1974. J. Invest. Derm. 62, 394-405.

49. Matoltsy, A. G. 1975. J. Invest. Derm. 64, 127-142.

50. Ugel, A. 1971. J. Cell Biol. 49, 405-422.

51. Sugawara, K. and Bernstein, I. A. 1971. Biochim. Biophys. Acta 238, 129-138.

52. Kumaroo, K. K., Gray, R. H., Kaman, R. L. and Bernstein, I. A. 1972. J. Invest. Derm. 59, 305-312.

53. Aviv, H. and Leder, P. 1972. Proc. Nat'l Acad. Sci., U.S., 69, 1408-1413.

54. Bernstein, I. A., Kaman, R. L., Malinoff, M., Sachs, M. S. and Gray, R. H. 1975. J. Invest. Derm. 65, 102-106.

55. Sachs, L. and Bernstein, I. A. 1975. Fed. Proc. 33, Abst.

56. Bonner, J., Chalkley, G. R., Dahmus, M., Fambrough, D., Fujimura, D., Fujimura, F., Huang, R. C., Huberman, J., Jensen, R., Marushigl, K., Ohlenbusch, H., Olivera, B. and Widholm, J. 1968. Methods in Enzymol. 12B, 3-65.

57. Terada, M., Cantor, L., Metafora, S., Rifkind, R. A., Bank, A. and Marks, P. A. 1972. Proc. Nat'l Acad. Sci., U.S., 69, 3575-3579.

58. Ross, J., Gielen, J., Packman, S., Ikawa, T. and Leder, P. 1974. J. Mol. Biol. 87, 697-714.

59. Iio, T. and Tamaoki, T. 1974. Nature 252, 495-497. 